\title{
Enthymemes in Dialogue
}

\subsection{Introduction}

In the previous chapters we have looked at enthymematic arguments and topoi in the context of pragmatics and interactional linguistics. We have seen that rhetorical reasoning is intimately related to the kind of inferences that are the focus in pragmatics, and that the usage of enthymemes exploits foundational principles of interactional linguistics such as dialogicity and grounding. However, although we have demonstrated the relevance of the enthymeme in interactive linguistics, we have not yet presented a theoretical framework which may be used for precise analyses of enthymematic reasoning.

In this chapter we will work our way towards a more detailed account of enthymemes and topoi and the role they play in interaction. First, we will discuss some concepts which are important for the subsequent analysis, and then we will move on to look at some examples. We will take as our point of departure an information state update approach as described by Larsson and Traum (2000) and Larsson (2002), including questions under discussion (QUD), as developed by Ginzburg (1994, 1996, 1998), Cooper et al. (2000) and Ginzburg (2012). We will look at how we can account for various types of examples involving enthymemes and topoi. Our analysis will especially focus on the different types of accommodation which are necessary for dialogue participants to be able to draw on rhetorical resources made up of sets of topoi.

The formal framework we will use is TTR, a type theory with records Cooper (2005a, 2012, 2016). ${ }^{1}$ TTR is a rich type theory, which has been successfully employed to account for a range of linguistic phenomena, including ones particular to dialogue (Cooper, 2005b; Ginzburg, 2012; Cooper and Ginzburg, 2015; Lücking, 2016).

1 The reference Cooper (2016) refers to an unpublished stable draft, dated 2016-11-3o. When needed, we will refer to a later draft, accessed 2020-o6-29, as Cooper (2020). See bibliography for URLS. 
There are several reasons for choosing TTR for dialogue modelling. Cooper (2005b) shows how important aspects of semantic theories such as DRT (Kamp and Reyle, 1993), situation semantics (Barwise and Perry, 1983), and work in the Montague tradition (Montague, 1973) may be cast in TTR. This means that the various problems that these theories were designed to solve may be solved within a single framework. Thus, choosing TTR for the account presented here means we can relate enthymemes and topoi to the issues addressed in these important semantic theories.

Ginzburg (2012) points out that TTR (like other rich type theories) has the advantage of being able to handle utterances as well as utterance types, which is crucial for analysing meta-communicative aspects of interaction. This is a great advantage for us as we are sometimes simultaneously interested in the meaning conveyed by a particular utterance and the role which that type of utterance plays in an enthymematic argument. The TTR notion of subtyping is also important for our account of how we employ topoi in different kinds of enthymemes through operations like restriction, generalisation and composition. In TTR we have a convenient way of doing this since we have record types-structured types where we can easily add and remove fields.

Another advantage of TTR is that it offers a way to formally account for natural language without employing the concept of possible worlds. Ranta (1994), Cooper (2005a), Larsson (2011), Cooper and Ginzburg (2012), Fine (2012), Lappin $(2013,2015)$ and Chatzikyriakidis (2014), among others, point out problems with possible-worlds accounts of meaning. These objections are of a philosophical and semantic as well as a computational nature. The computational issues might not be immediately relevant to us, but they would be relevant if we wanted to take our analysis further and implement aspects of it in a dialogue model, for example.

\subsubsection{Some Basic Concepts of TTR}

TTR is based on the fact that humans (and animals) perceive the world in terms of categories or types. Not only do we have the ability to classify things in the world as individuals (corresponding to entities) - which could in itself be seen as typing - but also to categorise them as being of particular types. The identifying of individuals as individuals (individuation) as well as the typing is relative to the physical and cognitive prerequisites of the perceiving agent as well as environmental factors. For example, a human watching a tree from a distance might have no problem identifying it as an entity and recognising it 
as being of the type Tree, while an ant never gets the macro-perspective that enables the human to perceive the tree as one entity. The ant might instead be able to identify ridges in the bark of the tree as obstacles that need to be overcome in order to reach the anthill. Thus it is not only the conditions of the agent that limits its ability to identify entities and type them, it is also the properties of the objects themselves. The likelihood of an agent typing something in a particular way is related to factors such as what the agent can do in relation to the object. These relations between agents and objects are often referred to as affordances (Gibson, 1977). For a detailed discussion about the way perception and the world is seen as connected to types in TTR, see Cooper (2016).

In formal terms, we can describe the judgement that a particular object, $a$, is of a certain type $T$, as $a: T$. In TTR the basic type of objects such as humans, animals and things, corresponding to entity or $e$ in Montague semantics (Montague, 1973), is Ind, the type of individuals.

Basic types in TTR are types which are not constructed from other objects in the theory. Examples are Ind for individuals and Real for real numbers. One way to construct more complex types is to use predicates. From predicates we can construct ptypes. A ptype consists of a predicate and its arguments, for example see $(a, b)$, " $a$ sees $b$ ". Objects which belong to ptypes are for example events and states. If a type, for example $T_{1}$, is realised, there is something of type $T_{1}$. We say that this object is a proof or witness of $T_{1}$. The existence of some particular object $a$ of type $T_{1}$ is a proof that there exists something of type $T_{1}$.

In order to represent complex situations which potentially involve many ptypes and individuals, as well as other more general types, we use record types. A record type is a structure of pairs of labels and types. The same letters that are often used as individual variables in other systems- $\mathrm{x}$, y, etc.- are used as labels associated with the type Ind, and the label $\mathrm{c}$ with different subscripts is used for constraints on the type of situation represented by the record type. In (3.1) we see an example of a record type representing a type of situation where a dog runs.

$$
\left[\begin{array}{l}
\mathrm{x}: \text { Ind } \\
\mathrm{c}_{\operatorname{dog}}: \operatorname{dog}(\mathrm{x}) \\
\mathrm{c}_{\mathrm{run}}: \operatorname{run}(\mathrm{x})
\end{array}\right]
$$

The object to which the label ' $x$ ' points in (3.1) is of type Ind, and there are two constraints on the type of situation, that this individual is a $\operatorname{dog}\left(c_{\operatorname{dog}}: \operatorname{dog}(x)\right)$ and that it runs $\left(\mathrm{c}_{\mathrm{run}}: \mathrm{run}(\mathrm{x})\right)$. In addition to record types we also want to be able 
to talk about situations that are witnesses of record types. We represent such objects as records. A record is a structure where the labels are associated with values rather than types. The label and the value are separated by an equals sign. In (3.2) we see a record representing one particular situation. This situation is of the type in (3.1) if all the values are of the appropriate types (a : Ind, $\left.\mathrm{s}_{1}: \operatorname{dog}(\mathrm{a}), \mathrm{s}_{2}: \operatorname{run}(\mathrm{a})\right)$. If these conditions are fulfilled, the record in $(3.2)$ is a witness of (3.1).

(3.2) $\left[\begin{array}{l}\mathrm{x}=\mathrm{a} \\ \mathrm{c}_{\mathrm{dog}}=\mathrm{s}_{1} \\ \mathrm{c}_{\mathrm{run}}=\mathrm{s}_{2}\end{array}\right]$

Let us assume that we want to talk about a type of situation where a particular dog-Spot—runs. We can do that by making a field in our record type manifest. This means that we let a label be associated with both a value and a type, as illustrated in (3.3).

$$
\left[\begin{array}{l}
\mathrm{x}=\text { Spot }: \text { Ind } \\
\mathrm{c}_{\mathrm{dog}}: \operatorname{dog}(\mathrm{x}) \\
\mathrm{c}_{\mathrm{run}}: \operatorname{run}(\mathrm{x})
\end{array}\right]
$$

\subsubsection{Subtyping in TTR}

Record types in TTR offer a structured way of representing subtyping, which can be used-among other things - to account for how speech situations relate to each other. A type $T_{1}$ is a subtype of $T_{2}\left(T_{1} \sqsubseteq T_{2}\right)$ just in case for any $a, a: T_{1}$ implies $a: T_{2}$, no matter what is assigned to the basic types and ptypes (Cooper, in prep, p. 39). For a record type $T_{1}$ to be a subtype of another record type $T_{2}$, there cannot be any label-type pairs in $T_{2}$ which do not exist in $T_{1}$, and there can be no manifest field in $T_{2}$ that is absent in $T_{1}$. For example, the record types in (3.4b), (3.4c) and (3.4d) are all subtypes of the record type in (3.4a). The record type in (3.4d) is also a subtype of the record types in $(3.4 \mathrm{~b})$ and (3.4c). The record types in (3.4b) and (3.4c) are not in a subtype relation to one another, since (3.4c) involves a manifest field which is not present in (3.4b), and (3.4b) involves a label-type pair that is absent in (3.4c).
a. $\left[\begin{array}{l}\mathrm{x}: \text { Ind } \\ \mathrm{c}_{\mathrm{dog}}: \operatorname{dog}(\mathrm{x})\end{array}\right]$
b. $\left[\begin{array}{l}\mathrm{x}: \text { Ind } \\ \mathrm{c}_{\mathrm{dog}}: \operatorname{dog}(\mathrm{x}) \\ \mathrm{c}_{\mathrm{run}}: \operatorname{run}(\mathrm{x})\end{array}\right]$ 

c. $\left[\begin{array}{l}\mathrm{x}=\text { Spot : Ind } \\ \mathrm{c}_{\mathrm{dog}}: \operatorname{dog}(\mathrm{x})\end{array}\right]$
d. $\left[\begin{array}{l}\mathrm{x}=\text { Spot }: \text { Ind } \\ \mathrm{c}_{\mathrm{dog}}: \operatorname{dog}(\mathrm{x}) \\ \mathrm{c}_{\mathrm{run}}: \operatorname{run}(\mathrm{x})\end{array}\right]$

For an in-depth introduction to records and record types including formal definitions, see Cooper (2005b), Cooper (2012), Cooper and Ginzburg (2015) and Cooper (2016).

\subsubsection{The Dialogue Gameboard}

Now that we have introduced basic types like Ind, ptypes, record types and records, we will move on to how we do dialogue semantics in TTR. We will start out as simply as possible and add new features along the the way. To model the information states of dialogue participants, we will employ the concept of dialogue gameboards (DGB). Following others-most famously Wittgenstein (1953) - Lewis (1979) used the metaphor of language use, particularly conversation, as a game. Lewis claimed that the development of a conversation can be seen in terms of a score analogous to that of a game like baseball. In baseball the score consists of numbers, the number of strikes, runs, etc. In a language game the score is made up of sets of moves, questions, presuppositions, commitments, and other linguistic features which are relevant in the discourse. Lewis also introduced the idea of a scoreboard which keeps track of the progress of the dialogue.

The DGB is Ginzburg's take on the scoreboard approach to dialogue analysis (Ginzburg, 1996, 1998, 2012; Ginzburg et al., 2010; Cooper and Ginzburg, 2012) and an important feature of his theory of dialogue semantics-KoS- which has been developed over the last couple of decades.

However, in this body of work there are no suggestions regarding how to handle enthymematic arguments or topoi. Since our main objective is to account for the role enthymemes and topoi play in dialogue, we do not commit to any particular setup of the DGB from previous literature. However, the model we present here is influenced by previous work in terms of the layout of the DGB. We suggest a version of the DGB which includes enthymemes and topoi, and accounts for how they may interact with each other and with various contextual and co-textual factors. For background on gameboard semantics in TTR we recommend the literature referred to above, particularly Ginzburg (2012) and Cooper (2016).

Following Cooper (2016) we will treat the information state of a conversational participant as a record, and the dialogue gameboard that represents the 
type of this information state as a record type. This means that the structures we will deal with usually represent the types of particular information states rather than the information states themselves. Thus the dialogue gameboard of an agent $A$ is a type of agent $A$ 's information state.

We are interested in how conversational and contextual features are introduced and integrated in the discourse model. Our focus is particularly on how individual agents draw on individual (and sometimes distinct) resources. The examples in this section will therefore be described and analysed using separate gameboards for each agent, representing the types of their respective information states. Ginzburg (1998), Larsson (2002), Ericsson (2005), and Ginzburg (2012) all choose this approach.

Larsson and Traum (2000) suggest the possibility of one gameboard depicting an objective take on the development of the dialogue, corresponding to a God's eye perspective on the state of the dialogue, rather than the context as perceived by the speakers themselves. However, such a notion of context does not help us handle dialogue features like misunderstanding, repetition, clarification, etc. To capture such phenomena we must have separate representations for the respective information states of individual dialogue participants, capturing something that more resembles the common ground assumed by each dialogue participant.

The concept of common ground (Stalnaker, 1978; Clark et al., 1991; Clark, 1996) is usually taken to mean the things that are taken for granted by an agent as being shared with the other agents involved in conversation, or, to be more precise, the things which this agent behaves as if he took for granted, and which are in some way relevant in the interaction. Thus, the concept of common ground is similar to the information we display on the shared part of the dialogue gameboard.

We see the information state of a dialogue participant as comprising two types of information - the kind that the dialogue participant takes to be shared in the context of the conversation, and the kind that he takes to be private. Therefore we keep the basic divide between private and shared which we find in Larsson (2002), Ericsson (2005) and Ginzburg (2012). Let us say for example that the type of an agent's private information state is $T_{p}$ and the type of the same agent's shared information state is $T_{s}$, then, in (3.5), we have the type of that agent's information state.

$$
\left[\begin{array}{l}
\text { private }: T_{p} \\
\text { shared }: T_{s}
\end{array}\right]
$$




\subsubsection{Agenda}

The type associated with the label 'shared' is a record type representing the agent's take on what is shared information in the dialogue situation. That is, what has in some way been referred to in the dialogue, or what is necessary to integrate in the information state for a dialogue contribution to be interpreted in a relevant way. For example, although a topos may be of central relevance in the dialogue, it does not appear on the gameboard as part of an agent's shared information state until it has been made explicit, or until something has been said which has caused it to be accommodated. Similarly, the type associated with the label 'private' is a record type representing the agent's take on what he himself believes but might not be known by other dialogue participants.

We start out by introducing the most basic features of the gameboard and their functions, starting with the fields that belong to the private section of the gameboard. We represent the intention of an agent to make a specific move in terms of a private agenda. The kind of objects that would be on an agenda in the information state of a dialogue participant are dialogue moves that the dialogue participant intends to make in the dialogue. Since we want to be able to account for an agenda involving more than one move, we will eventually model the type of the agenda as a list of move types. For now however, it suffices to let the agenda be of a, as yet unspecified, type $T_{a g}$.

$$
\left[\begin{array}{l}
\text { private }:\left[\text { agenda }: T_{a g}\right] \\
\text { shared }: T_{s}
\end{array}\right]
$$

\subsubsection{Project}

The agenda is related to the field 'project', which we introduce under 'shared'. The term is inspired by Linell's (2009) concept of communicative project, which is reminiscent of Wittgenstein's language game. On Linell's account, a communicative project is a jointly accomplished communicative action, typically carried out over several utterances. Linell relates it to the notion of communicative activity, as described in Allwood (2000), in that a communicative activity is a comprehensive communicative project tied to a socio-cultural situation type.

Another related concept is that of conversational genre, used for example by Ginzburg (2010), to, among other things, account for relevance in dialogue. The concepts of genre and activity are similar, but differ in the perspective from which they are defined. For Ginzburg, a genre is defined by issues that are typically raised in a conversation of that genre. In Allwood's theory an activity type is characterised by the goals and roles that are associated with it. Thus, genre seems to be more of a linguistic category according to which conversations may be analysed, while activity is not necessarily a linguistic category- 
even though most social activities involve linguistic behaviour. The concept of activity can thus be used to predict events that give rise to particular types of conversations.

We perceive activity types as part of agents' resources, where they are represented as types of re-occurring sequences of events. ${ }^{2}$ which aim to fulfil the same type of goal. Each instance of an activity also often follows a recognisable pattern. Examples of distinguishable activities are board meeting, dinner conversation, medical consultation, etc. The event types that make up the sequences which constitute an activity can be more or less obligatory, both in terms of the type of events and in terms of the order in which the events occur. These events may themselves be described in terms of sequences of subevents, that is, communicative projects. For now we will not get into details about the formal representation of the project, but simply represent it as a type $T_{p r}$

When we think of a project that is to be jointly carried out, we do not necessarily specify which dialogue participant is supposed to be responsible for carrying out specific parts of the project. For example, if Kay and Sam are decorating their new house, the project of agreeing on where to place a specific armchair does not necessarily contain information about who is supposed to make what move. Correspondingly, the project is associated with one or more conversational games specifying the type of moves that different agents involved in the game are allowed to make in relation to each other (provided they keep playing the game), regardless who the agents are. For example, if one dialogue participant makes a suggestion, the other should evaluate and respond. We will leave these games aside for the moment, and return to them when we consider updates of the dialogue gameboard in Chapter 5 .

For the purpose of accounting for our data it is sufficient to consider the communicative project as something which is perceived as shared information by all dialogue participants. However, there is no reason in principle why we could not expand the 'private'-field to include private communicative projects to represent "hidden agendas", etc.

\subsubsection{Questions under Discussion, Latest Move, and Commitments}

Apart from 'project', we will consider three additional fields under 'shared' on the dialogue gameboard-Questions under Discussion ('qud'), Latest Move ('lm') and Commitments ('com') The items on 'qud' represent questions which

2 Following Fernando (2006) and Cooper (2016), we will formalise sequences of communicative events as strings of events. We will return to this in Section $5 \cdot 3$. 
have been raised in the dialogue, explicitly or implicitly. We will give a detailed account for how we model questions later on. For now we will use the shorthand $T_{q}$ to represent the type associated with the label 'qud'.

The term facts used by Ginzburg is associated with truth and falsity, which might not necessarily be desirable in the context of accounting for the progress of a dialogue-dialogue participants may believe something to be true which is false, and they may knowingly accept untrue things "for the sake of the argument". Larsson (2002) and Ericsson (2005) emphasise the aspect of mutual agreement by introducing commitments instead of facts. We will use commitments ('com') for propositions that have been grounded in the dialogue. For the time being we refer to the type associated with 'com' as $T_{\text {com }}$. The type associated with ' $\mathrm{l}-\mathrm{m}$ ' is a record type featuring information such as speaker, move type, utterance content, etc. However, for now we refer to this as a type $T_{l-m}$.

The figure in (3.7) shows a dialogue gameboard where the shared field has been further specified as described above. In the next section, we will define the types of the various fields in the DGB in the course of analysing a simple dialogue.

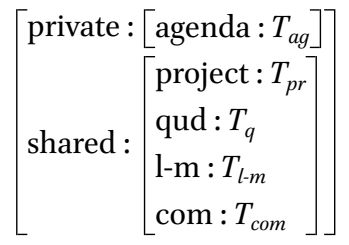

\subsection{Analysing a Simple Dialogue}

Let us now explore the possibilities of the gameboard by considering the simple dialogue between agents $A$ and $B$ in (3.8).

$$
\begin{aligned}
& \text { a. } A \text { : Do you have the time? } \\
& \text { b. } B \text { : It's three thirty. }
\end{aligned}
$$

This dialogue is made up of a standard question-answer sequence without repairs, clarifications or the like. Let us first consider $A$ 's initial information state. $A$ wishes to find out what time it is, which causes an agenda item to be added to her DGB.

As we have previously seen, manifest fields allow us to let a label be associated not only with a type but with an object of a type. For example, $\left[\mathrm{a}: T_{1}\right]$ 
means that objects associated with the label "a" are of type $T_{1}$. If we have such an object, for example the child Sam, we may say that $\left[\mathrm{a}=\mathrm{Sam}: T_{1}\right]$. However, if we want the object associated with the label to be a type, for example a record type which includes some information about Sam, the type of this type is RecType, the type of record types. We will represent projects and commitments as record types, and hence we take $T_{p r}$ and $T_{c o m}$ to be RecType.

The objects that could go on the agenda are types of moves that an agent is intending to make in an interaction, and we represent these as record types. However, since a dialogue participant may well plan more than one move in advance, we want the object on the agenda to be a list of record types where each type corresponds to one type of move. We call the type of a list a list type (Cooper, 2016, p. 267). If an object is a list of record types-for example $T_{1}$ and $T_{2}$-it is of the type list(RecType). We write this as $\left[T_{1}, T_{2}\right]: \operatorname{list}(\operatorname{Rec}-$ Type).

The type of A's initial information state can be seen in (3.9). The type on the agenda is a record type representing the type of move that is employed when asking about the time. We refer to this type using $T$ with a subscript providing a rough description of the function of such move.

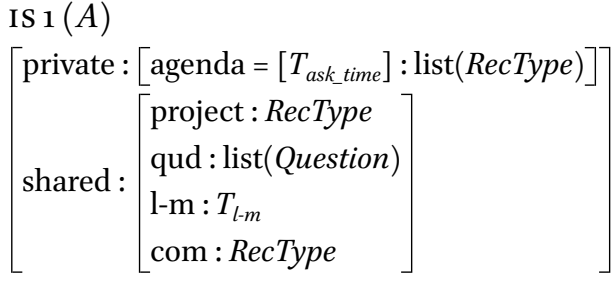

When $A$ has uttered (3.8a), the move realised by this utterance is added to the 'l-m' field of the DGB, and the first item on the list on the agenda is taken off (which in this case means that we have an empty list on the agenda). We see the type of $A$ 's information state after the utterance of (3.8a) in (3.10):

(3.10) IS $2(A)$

$$
\left[\begin{array}{c}
\text { private : }[\text { agenda }=[]: \operatorname{list}(\text { RecType }) \\
\text { shared : }\left[\begin{array}{l}
\text { project }: \text { RecType } \\
\text { qud }: \text { list }(\text { Question }) \\
\text { l-m }: T_{\text {ask-time }} \\
\text { com }: \text { RecType }
\end{array}\right]
\end{array}\right]
$$

We assume that the updates directly following the uttering of (3.8a) are identical for agents $A$ and $B$. Integrating the lates move of type $T_{\text {ask-time }}$ results in 
updates of 'project' and 'qud'. $A$ and $B$ both expect their interlocutor to recognise that an utterance like (3.8a) aims at initiating a project to find out the time. Agent $A$ is obviously aware of this project at an earlier stage, but does not expect it to be shared until a move of type $T_{\text {ask-time }}$ is made. Likewise for the update of 'qud' - the question $T_{\text {time? }}$ that is pushed onto 'qud' can be expected to be similar for any speaker of English, given the content of (3.8a). To make it possible to track more than one question under discussion, 'qud' is set up as a list in a similar way to the agenda, so $T_{q}=\operatorname{list}($ Question). Thus, at the point when 'l-m', 'project' and 'qud' have been updated, the DGB of agent $B$ is identical to that of $A$. We see this gameboard in (3.11):

(3.11) IS $3(B)$

$$
\left[\begin{array}{l}
\text { private : } \\
\text { shared }:\left[\begin{array}{l}
{[\text { agenda }=[]: \operatorname{list}(\text { RecType })} \\
\text { qud }=\left[T_{\text {timee }}\right]: \operatorname{list}(\text { Question }) \\
\mathrm{l}-\mathrm{m}: T_{\text {ask-time }} \\
\operatorname{com}: \operatorname{RecType}
\end{array}\right]
\end{array}\right]
$$

Next, $B$ 's information state is updated with an item on the agenda representing the next move he intends to make in the dialogue, that is answering the question under discussion by telling $A$ what time it is, and thereby also carrying out the communicative project at hand.

$(3.12)$ IS $4(B)$

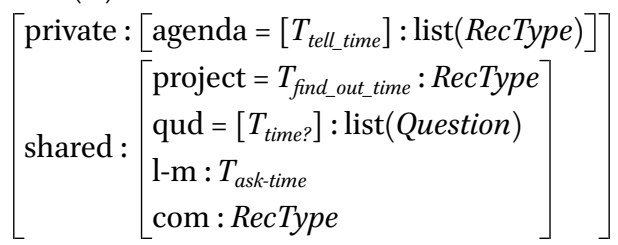

A move of the type on $B$ 's agenda $\left(T_{\text {tell_time }}\right)$ is carried out by his saying $(3.8 \mathrm{~b})$. At this point, a commitment that the time is three thirty is integrated on the DG B $\mathrm{S}$ of both dialogue participants. The interlocutors now expect it to be common ground that the time is three thirty (unless, of course, there is reason to believe that $B$ is not telling the truth).

The agenda item is therefore taken off his DG B and 'I-m' is updated for both agents. In addition, the question on 'qud' is resolved, and thus popped off, and the project is carried out. The final information state in this mini-dialogue (for both participants) would thus be of the type in (3.13): 
(3.13) Is $5(A$ and $B)$

$\left[\begin{array}{l}\text { private : } \\ \text { shared }:\left[\begin{array}{l}\text { agenda }=[]: \operatorname{list}(\text { RecType })] \\ \text { qud }=[]: \operatorname{list}(\text { Question }) \\ 1-\mathrm{m}: T_{\text {tell-time }} \\ \text { com }=T_{\text {three_thirty }}: \text { RecType }\end{array}\right]\end{array}\right]$

\subsection{Introducing Enthymematic Reasoning on the DG B}

A simple question-answer exchange like the one in (3.8) can be handled with the gameboard features we have introduced so far. Let us now turn to a slightly more complex sequence and see if these features are still enough, or if there are some aspects of the interaction that we cannot capture if we stick to the current set up of the dialogue gameboard. The example in (3.14) depicts a situation where a person $A$ asks another person $B$ where he wants to go and then informs him of a suitable route. However, $B$ does not seem convinced this is the optimal route and so asks for a reason why this particular route is preferable. $A$ provides a reason, and $B$ explicitly accepts.
(3.14) a. $A$ : Where do you want to go?
b. $B$ : I want to go home
c. A: Let's take the bypass!
d. $B$ : Why the bypass?
e. $A$ : It's shorter
f. $B:$ OK.

This dialogue, though made up, contains many characteristics of conversation, such as questions (Where do you want to go?, Why the bypass?) and feedback (OK).

Let us imagine a situation where $A$ is $B$ 's designated driver (or a dialogue agent in a speech interface for a GPS). Thus, we assume that some communicative project aiming at deciding where to go and how to get there is initially on dialogue participant $A$ 's DG B. We refer to the type of this project as $T_{\text {plan_route }}$ and represent it as a record type, but as in the previous section we will not worry about exactly what that record type looks like just yet. Let us assume that this project has caused an update of $A$ 's agenda so that it contains an item specifying the next type of move which $A$ intends to make in the dialogue. We will refer to this move type as $T_{\text {ask_destination. }}$. In (3.15) we see $A$ 's gameboard before any utterance has been made. 
(3.15) IS $1(A)$

$$
\left[\begin{array}{rl}
\text { private : } & {\left[\text { agenda }=\left[T_{\text {ask_destination }}\right]: \operatorname{list}(\text { RecType })\right]} \\
\text { shared }: & {\left[\begin{array}{l}
\text { project }=T_{\text {plan_route }}: \text { RecType } \\
\text { qud }: \operatorname{list}(\text { Question }) \\
\text { l-m }: T_{l-m} \\
\text { com }: \text { RecType }
\end{array}\right]}
\end{array}\right]
$$

In (3.16) we see $B$ 's DGB before any utterance has been made. We assume that $B$ has a similar idea about the communicative project at hand. $B$ 's communicative project is thus of the same type as $A$ 's. Let us also assume that $B$ expects $A$ to make the first move in the dialogue, for which reason $B$ 's agenda is initially empty.

$(3.16)$ IS $2(B)$

$$
\left[\begin{array}{l}
\text { private : }[\text { agenda }=[]: \operatorname{list}(\text { RecType })] \\
\text { shared }:\left[\begin{array}{l}
\text { project }=T_{\text {plan_route }}: \text { RecType } \\
\text { qud }: \text { list }(\text { Question }) \\
\text { l-m }: T_{l-m} \\
\text { com }: \text { RecType }
\end{array}\right]
\end{array}\right]
$$

In (3.17) we see $A$ 's information state just after having asked the question "where do you want to go?", (3.14a). The move type $T_{\text {ask_destination }}$ is taken off the agenda, and a corresponding move appears on 'l-m'. A question, which we refer to as $T_{\text {where_to? }}$ is pushed onto 'qud'.

$$
\begin{aligned}
& \text { (3.17) Is } 3(A) \\
& {\left[\begin{array}{l}
\text { private }:[\text { agenda }=[]: \operatorname{list}(\text { RecType })] \\
\text { shared }:\left[\begin{array}{l}
\text { project }=T_{\text {plan_route }}: \text { RecType } \\
\text { qud }=\left[T_{\text {where_to? }}\right]: \operatorname{list}(\text { Question }) \\
1-\mathrm{m}: T_{\text {ask_destination }} \\
\text { com }: \text { RecType }
\end{array}\right]
\end{array}\right]}
\end{aligned}
$$

After $A$ 's first utterance $B$ 's information state is also updated similarly to $A$ 's information state above. After this update, the question on 'qud' results in a move type $T_{\text {reply_go_home }}$ to appear on the agenda. In (3.18) we see the type of $B$ 's information state at this point. 
$(3.18)$ IS $4(B)$

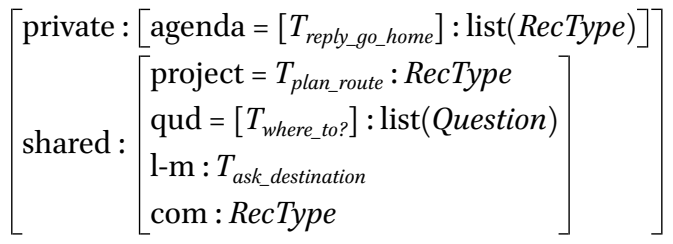

When $B$ makes the utterance "I want to go home", (3.14b), $T_{\text {reply_gonome }}$ is taken off the agenda, along with the question on 'qud'. The field 'l- $\mathrm{m}$ ' is updated with $T_{\text {reply_go_home }}$ and the commitment that $B$ wants to go home, $T_{B_{-} \text {wants_home }}$ is integrated. In (3.19) we see $B$ 's DGB at this stage in the conversation.

(3.19) IS $5(B)$

$$
\left[\begin{array}{l}
\text { private }:[\text { agenda }=[]: \operatorname{list}(\text { RecType })] \\
\text { shared }:\left[\begin{array}{l}
\text { project }=T_{\text {plan_route }}: \text { RecType } \\
\text { qud }=[]: \operatorname{list}(\text { Question }) \\
\text { l-m }: T_{\text {reply_go_home }} \\
\text { com }=T_{B_{-} \text {wants_home }}: \text { RecType }
\end{array}\right]
\end{array}\right]
$$

\subsubsection{Topoi as Resources for Inventing Arguments}

Thus far the dialogue proceeds according to the principles we introduced in the previous question-answer exchange. Now we want a move type with the content propose route or similar to appear on $A$ 's agenda. If we imagine the situation being such that there is only one available route which leads "home", this exchange would be similar to the previous ask-for-time exchange. However, as the dialogue in (3.14) is set up, we can assume that there are a number of possible routes and that the choice made is largely dependent on preferences.

Since preferences vary between agents and contexts, we may think of the principle supporting a particular preference not as an absolute rule but as a topos. Let us say, for instance, that there are three possible routes in the scenario in (3.14). We may refer to them as the bypass, the bridge route and park lane. The bypass is the shortest route, park lane is the cheapest (since it is not a toll road), and the bridge route is most scenic. We assume that an individual engaged in the conversation has access to three topoi that may be drawn on in arguments regarding which of the three routes to choose, as seen in $(3.20):^{3}$

3 In classical rhetoric there is usually a division between deliberative rhetoric, that is arguing for what should be done, and forensic rhetoric, where arguments concern what has happened 
(3.20) $\tau_{\text {shorter }}$ : "If you choose between routes, choose the shortest one" $\tau_{\text {scenic }}$ : "If you choose between routes, choose the most scenic one" $\tau_{\text {cheap }}:$ "If you choose between routes, choose the cheapest one"

A dialogue participant who has access to these three topoi about preferences for routes, and (unlike the situation in (3.14)) wishes to make the argument that the bridge route is the preferable route, may thus suggest the bridge route, provide the premise that it is most scenic, and expect this enthymeme to be accepted based on the topos $\tau_{\text {scenic }}$ as seen in (3.21):

$$
\frac{\text { the bridge route is the most scenic }\left(\tau_{\text {scenic }}\right)}{\text { let's take the bridge route }}
$$

\subsubsection{Private and Shared Topoi}

Topoi may thus be drawn upon to invent arguments. The invention of an argument based on a topos can happen before a suggestion is made. In the dialogue in (3.14) this would involve dialogue participant $A$, perceiving that agent $B$ wants to go home, evaluating the possible routes and their qualities in relation to available topoi. $A$ then suggests the route that is most advantageous in relation to the most salient topos. On this scenario, the topos underpinning the argument is already clear to the speaker before the suggestion of route is made, and the agent may choose to explicitly include a reason for the suggestion, for example "Let's take the bridge route, it's the most scenic", in her utterance. It is also possible, of course, that the suggestion made was selected by chance, or for a reason the speaker does not want to be known. In such case the reasoning about salient topoi may come after the suggestion.

In short, it may be the case that the topos on which the argument is based is the one the speaker believes most persuasive to an interlocutor-not the topos that the speaker herself finds most convincing. In our present scenario, for example, if $A$ were to suggest a scenic-but longer-route without justifying it, $B$ might think that she has no idea what she is talking about and that she is suggesting a route at random. If she, on the other hand, were to say -Let's take the bridge-route-it's more scenic!, $B$ might accept the proposal

in a particular case Corbett and Connors (1999). In the former of these, the conclusion of the enthymematic argument is typically an imperative, in the second it is a declarative. The same topos can be drawn on to underpin any argument, and the mode of the consequent is a matter of the enthymeme, not the underpinning topos. However, at this point we will assume that the consequents of these topoi themselves involve imperatives. 
even if he himself would have preferred the bypass on the grounds of it being the shortest possible route.

Because of this double use of topoi-on the one hand they influence our suggestions and givings of reasons, on the other we count on them being shared in discourse-we introduce private topoi, for producing and evaluating claims, proposals, suggestions, etc., and shared topoi for keeping track of the topoi a dialogue participant counts on being jointly accessible in a conversation.

$B$ 's statement that he wants to go home (3.14) $\mathrm{b})$ adds a move type $T_{\text {propose }}$ route to $A$ 's agenda. To know which route to suggest, $A$ must match one of the available routes with the most convincing reason for proposing a route. The relevant topoi in $A$ 's resources tell her that a good reason for proposing a particular route is that it is faster than other available routes. Her resources make it apparent that this reason for proposing a route is in fact many times more likely to be accepted than other possible reasons. For example, she might find a topos saying "if you are choosing between routes, choose the shortest one" $\left(\tau_{\text {shorter }}\right.$ in (3.4.1)). Intuitively, we may think of topoi as functions from one situation to a new type of situation. For example, if we have a situation where a choice is to be made regarding routes, we can predict a type of situation where we should choose the shortest one.

Eventually, we will model topoi as functions which return types. For now we will use variables based on the letter $\tau$. We also say for now that the type of topoi is Topos. Being the most salient topos for $A, \tau_{\text {shorter }}$ is integrated on $A$ 's private DGB, and she proposes a route accordingly: (3.22) represents $A$ 's information state just before she utters (3.14c), "Let's take the bypass".

$(3.22)$ Is $6(A)$

$\left[\begin{array}{rl}\text { private }: & \left.\begin{array}{l}\text { agenda }=\left[T_{\text {propose_bypass }}\right]: \operatorname{list}(\text { RecType }) \\ \text { topoi }=\tau_{\text {shorter }}: \operatorname{list}(\text { Topos })\end{array}\right] \\ \text { shared }: & {\left[\begin{array}{l}\text { project }=T_{\text {plan_route }}: \text { RecType } \\ \text { qud }=[]: \operatorname{list}(\text { Question }) \\ \text { topoi }: \operatorname{list}(\text { Topos }) \\ \text { l-m }: T_{\text {reply_go_home }} \\ \text { com }=T_{B_{-} \text {wants_home }}: \text { RecType }\end{array}\right]}\end{array}\right]$

When $A$ has suggested the bypass, $B$ 's gameboard is updated as in (3.23). 
(3.23) Is $7(B)$
$\left[\begin{array}{l}\text { private : } \\ \text { shared : }\left[\begin{array}{l}\text { agenda }=[]: \operatorname{list}(\text { RecType }) \\ \text { topoi }: \operatorname{list}(\text { Topos })\end{array}\right] \\ \left.\begin{array}{l}\text { project }=T_{\text {plan_route }}: \text { RecType } \\ \text { qud }=[]: \operatorname{list}(\text { Question }) \\ \text { topoi }: \operatorname{list}(\text { Topos }) \\ \text { l-m }: T_{\text {propose_bypass }} \\ \text { com }=T_{\text {B_wants_home }}: \text { RecType }\end{array}\right]\end{array}\right.$

$B$ does not know anything about the bypass, and thus he does not know which of the accessible topoi that may be used to evaluate the proposal. He decides to elicit a reason by asking a Why?-question $T_{\text {ask_why_bypass }}$, and a question for the reason to choose the bypass is added to the agenda, asked, and pushed onto 'qud'. In (3.24) we see B's Is when he has just asked the question, but it has not yet been resolved.

$(3.24)$ IS $8(B)$

$$
\left[\begin{array}{rl}
\text { private : } & {\left[\begin{array}{l}
\text { agenda }=[]: \operatorname{list}(\text { RecType }) \\
\text { topoi }: \operatorname{list}(\text { Topos })
\end{array}\right]} \\
\text { shared }: & {\left[\begin{array}{l}
\text { project }=T_{\text {plan_route }}: \text { RecType } \\
\text { qud }=\left[T_{\text {why_bypass }:}\right]: \operatorname{list}(\text { Question }) \\
\text { topoi }: \operatorname{list}(\text { Topos }) \\
l-\mathrm{m}: T_{\text {ask_why_bypass }} \\
\text { com }=T_{B_{-} \text {wants_home }}: \text { RecType }
\end{array}\right]}
\end{array}\right]
$$

\subsubsection{Introducing the Enthymeme under Discussion}

After $B$ has asked $A$ for a reason for choosing the bypass, $A$ has to consider a reason which would make proposing a route acceptable. In principle, this reason may or may not match the private topos she herself had for proposing the bypass. However, if we assume that $A$ adheres to the maxim of quality, the topos underpinning the reason she presents in support of her suggestion is identical to the topos used for inventing it. Drawing on this topos, a move type reply is added to the agenda. 
$(3.25)$ IS $9(A)$

$$
\left[\begin{array}{rl}
\text { private }: & {\left[\begin{array}{l}
\text { agenda }=\left[T_{\text {reply_bp_shorter }}\right]: \operatorname{list}(\text { RecType }) \\
\text { topoi }=\left[\tau_{\text {shorter }}\right]: \operatorname{list}(\text { Topos })
\end{array}\right]} \\
\text { shared }:\left[\begin{array}{l}
\text { project }=T_{\text {plan_route }}: \text { RecType } \\
\text { qud }=\left[T_{\text {why_bypass? }}\right]: \text { Question } \\
\text { topoi }: \operatorname{list}(\text { Topos }) \\
\text { l-m }: T_{\text {ask_why_bypass }} \\
\text { com }=T_{B_{-} \text {wants_home }}: \text { RecType }
\end{array}\right]
\end{array}\right]
$$

To keep track of the enthymemes which are explicit in or can be construed from the dialogue, we introduce an enthymeme under discussion (eud) field. In some ways the concept of EUD is parallel to that of QUD. However, where questions tend to be resolved during the course of a dialogue, enthymemes are rather collected, compared and evaluated. For example, you might accept an enthymeme in principle, but present another enthymeme which you for some reason consider more important in the context.

After the utterance It's shorter (3.14e), the response is taken off $A$ 's agenda and a corresponding move appears on 'l-m'. The question is resolved and an enthymeme stating $A$ 's suggestion and her justification for that suggestion is pushed on 'eud'. Also, since $A$ presents the argument "We should choose the bypass since it is shorter", she expects a topos underpinning that argument to be shared after her utterance. Topoi warranting enthymemes in the dialogue appear on the 'shared' part on the DGB under 'topoi'. (3.26) represents $A$ 's information state after she has uttered (3.14e). Note that the field 'com' is also updated. The notation $T_{1}+T_{2}$ is used to indicate that the record type representing the commitments in the dialogue includes the commitments $T_{1}$ and $T_{2}$.

(3.26) IS $10(A)$

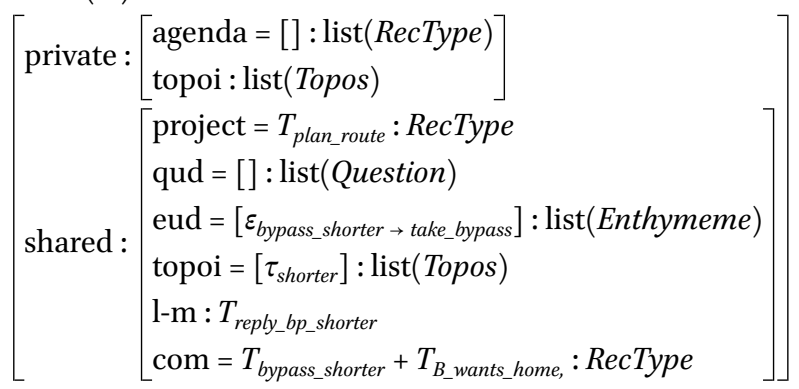

We now want to look at how $A$ 's reply is integrated in $B$ 's gameboard. $B$ happens to have the same rhetorical resources as $A$ regarding short routes, and he there- 
fore recognises $\tau_{\text {shorter }}$ as underpinning the enthymeme suggesting the bypass, and this appears in his information state as well. If we assume that $B$ accepts the suggestion if he accepts the reason for making the suggestion, the plan to take the bypass is also added to commitments.

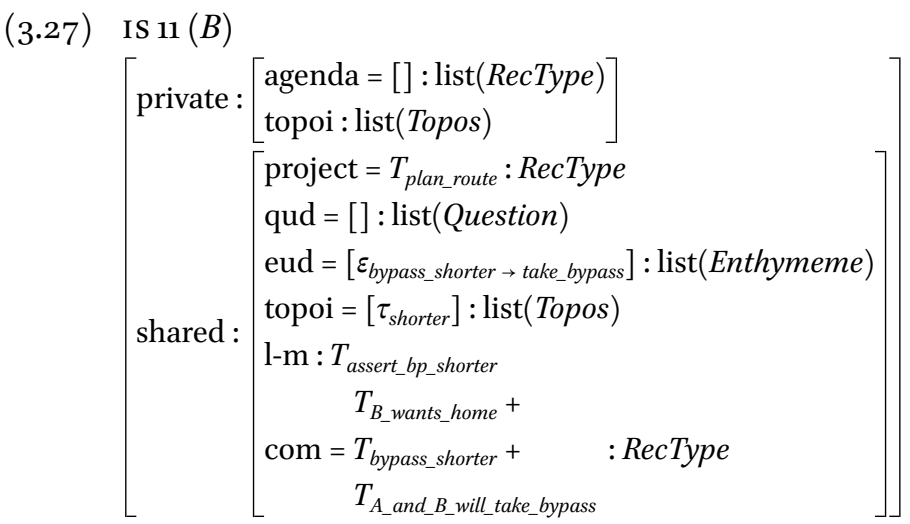

\subsection{Summary}

In this chapter we have sketched an account of dialogue involving enthymematic reasoning. We described the information state update approach to dialogue and introduced a basic version of TTR, a rich type theory that conveniently let us include contextual features in update rules for dialogue. We also looked at how subtyping in TTR can be used to account for relations between concepts and speech situations. We then described the general architecture of the DGB, and introduced a number of features which enable us to include enthymemes and topoi in a gameboard analysis of dialogue. We returned to the idea of accommodation of enthymemes and topoi introduced in Chapter 2, and presented an informal gameboard analysis of these phenomena.

We showed the progression of the information state update of the participants in our example dialogues, but not the actual update rules. The purpose of this is to introduce the idea of information state update in connection to enthymematic reasoning. In Chapter 4 we will present a more developed formal account including update rules. In Chapter 5 we will return to the issue of communicative projects and conversational games and provide an account of how these features contribute to the development of the dialogue and how they interact with enthymemes and topoi. 